\title{
48-hour ambulatory electrocardiography in dynamite workers and controls
}

\author{
C HOGSTEDT, ${ }^{1}$ B SÖDERHOLM, ${ }^{2}$ AND L BODIN ${ }^{3}$
}

From the Department of Occupational Medicine, Regional Hospital, Örebro, University Hospital, Linköping, ${ }^{1}$ the Department of Clinical Physiology, Regional Hospital, Örebro, ${ }^{2}$ and the Department of Statistics, University of Örebro, ${ }^{3}$ Sweden

ABSTRACT Sudden deaths and chronic cardiovascular diseases have been reported in excess frequency from the explosives industry. Forty-two active dynamite workers and 43 healthy, unexposed workers have been studied by ambulatory electrocardiographic monitoring during two 24-hour periods covering an exposed shift and the "abstinence phase," 40-64 hours after the last exposure to dynamite. To achieve comparability the non-exposed individuals were screened for risk factors of heart disease in the same way as those employed in exposed work. No statistically significant differences were found between the groups concerning the mean individual number of ventricular or supraventricular ectopic beats per hour or per 10000 heart beats during the whole recorded time. Among those who showed only ectopic beats in one of the two periods dynamite workers tended to have more ectopic beats in the second period. "Complicated" ventricular ectopic beats (multifocal, bigemeny, or coupled) were seen in six dynamite workers and four controls. The only observed period of ventricular tachycardia was seen in a dynamite worker on Monday morning. The mean individual corrected QT-time was similar between the two groups, and there was no tendency towards longer QT-times among the dynamite workers during the abstinence period. Continuous monitoring detected several cases with pronounced ventricular arrhythmias despite normal shorttime ECG and may be used to investigate the heart rhythm in active workers.

Sudden deaths in excess frequency have been reported from the explosives industry since the 1950s and so-called "Monday deaths" have occurred in the "abstinence phase"- that is, 36-72 hours after the last exposure to nitroglycol or nitroglycerin. ${ }^{12}$ Nitrate esters act as vasodilators immediately after absorption in the body and have been used as such in medicine for more than a century. Coronary vasospasm, however, has been shown in the abstinence phase as a withdrawal phenomenon and is thought to be the cause of the precordial pains often reported from dynamite workers during that time. ${ }^{3}$

Among men employed a long time in the explosives industries an increased risk of dying from chronic cardiocerebrovascular diseases might also be present. 45 The conditions of hygiene in the explosives industries have, however, improved considerably during the past two decades, ${ }^{6} 7$ but longitudinal, prospective epidemiological studies for evaluat-

Received 12 July 1979

Accepted 8 August 1979 ing a possible remaining risk from today's lower exposure levels would take a considerable time to complete. Therefore, supplementary methods for indicating cardiac disturbances have been sought, such as ambulatory 48-hour electrocardiographic monitoring.

In animal studies indications have been obtained that the sensitivity of the heart to epinephrine increases 24-48 hours after the last exposure to nitrate esters, resulting in an increased mortality of the exposed animals compared to controls and more frequent ventricular ectopic beats. ${ }^{8} 9$ Increases in sympathetic activity during myocardial ischaemia have been found to cause ventricular arrhythmias, including fibrillation, and prolonged QT-time. Prolonged QT-time has been associated with increased risk for sudden death in people with ischaemic heart disease. ${ }^{10}$ Furthermore, men with a large number of ventricular ectopic beats $(>100$ ) 10000 complexes) in electrocardiographic recordings run a significantly increased risk of death from coronary heart disease and sudden death. 1112

Lange $e t a l^{3}$ studied a nitroglycerin worker with 
coronary cineangiogram during the abstinence phase and showed coronary arteriospasm, which was readily reversed by nitroglycerin. We may entertain the hypothesis that the increased risk of sudden deaths among dynamite workers could be caused by ventricular fibrillation from an increased sympathetic activity during the abstinence phase combined with a relatively ischaemic myocardium because of coronary spasm in sensitive individuals. Such a hypothesis would be supported if the dynamite workers had more cardiac disturbances and longer QT-times compared with controls, especially in the abstinence phase. Continuous ECG recording could be used for displaying the cardiac rhythm during different periods, but only a few studies have been designed to examine the type or frequency of cardiac disturbances on continuous monitoring among healthy, working men screened for coronary heart disease. It was assumed that electrocardiographic abnormalities would reflect the effect of explosives on the incidence of sudden death, and with this assumption we undertook this study to assess the effectiveness of current environmental control by means of long-term electrocardiographic monitoring.

\section{Material and methods}

\section{SELECTION OF SUBJECTS AND HEALTH SCREENING}

Forty-nine healthy male dynamite workers, native Swedes, were available for study at the explosives factory of this investigation. They had been employed in dynamite work between four months and 27 years and had different degrees of exposure to dynamite. Their ages ranged from 18 to 62 . The controls were chosen from native Swedes who were employed at the same company but had never been occupationally exposed to dynamite.

Pre-employment examinations and annual health check-ups had excluded subjects with risk factors for heart disease from dynamite exposure. Therefore a similar screening procedure had to be applied among the controls to avoid selection bias. Exposed as well as unexposed subjects were examined and completed the (translated) self-administered version of the London School of Hygiene Cardiovascular Questionnaire. ${ }^{13}$ Questions were added about a family history of heart disease and high blood pressure among parents and siblings under the age of 61 and concerning smoking and alcohol habits (in the same categories as Doll and Hill $^{14}$ and Myrhed ${ }^{15}$ respectively).

The blood pressure was measured in the right arm with a standard mercury sphygmomanometer while the subject was seated. The diastolic pressure was recorded at the disappearance of the arterial
(Korotkov's) sounds. Serum cholesterol concentration was measured at the examination and checked with a fasting sample if the value was above the normal values, as recommended from the laboratory. Height and weight were measured. ECGs at rest were recorded for 30 seconds and read by the physiologist normally evaluating the ECGs from the dynamite workers but without knowing which group the subject belonged to.

As a result of the screening procedure some subjects had to be successively excluded from the control group because of ECG-changes that were regarded as "pathological" or "suspected pathological," hypertension $(>160 />90)$, hypercholesterolaemia $(>8$ $\mathrm{mmol} / \mathrm{l}$ for those older than 40 and $>7 \mathrm{mmol} / \mathbf{1}$ for younger individuals), a history of or treatment for heart disease, diabetes mellitus, alcoholism, hypertension, or asthma - that is, the same criteria that disqualify for dynamite work (either employment or continuation of exposed work). Thus after screening 65 control candidates 48 were accepted into the control group in this study.

\section{ECG MONITORING}

Four AVIONICS electrocardiocorders 385 were used to record two 24-hour periods from each of the 97 subjects. Three electrodes were used, one applied on the manubrium sterni and the two others on the right and left fifth ribs in the nipple lines, to give an apex position. After the ECG-signal had been checked the men returned to their normal activity. Recordings were made from 1300 on Friday to roughly the same time on Saturday, when the electrodes were taken away and the batteries charged. The subject returned on Sunday at about 1300 for the same procedure and was recorded until Monday noon. On Friday the dynamite workers went directly to their late shift work (1330-2200) while the great majority of the controls were working daytime (0700-1600). Saturday and Sunday were free for both groups. On Monday the dynamite workers had the early shift (0500-1330) while the controls worked the same hours as on Friday. This procedure allowed for recording during the last shift of the week for the exposed men, including the higher exposed cleaning operations, and during a substantial part of the abstinence phase (that is, during the period about 40-64 hours after the last exposed hour). Four subjects were recorded each week-end and attempts were made to register two exposed and two unexposed at the same time. The recordings started in September 1977 and the final recordings were made in May 1978. After each 24-hour registration the subjects were interviewed about their experiences during work, especially the exposure, and sleeping hours, leisure time, and types of activity. 
ANALYSES OF THE TAPES

The recordings were analysed on an AVIONICS composite electrocardioscanner combined with a Reynold's medical path-finder and a Mingograf 61 for paper-prints. The electrocardioscanner as well as the path-finder provide an oscilloscope display of the ECG at normal or 60 times standard speed. An arrhythmia event computer (Reynold's Medical PA 4) for counting ventricular or supraventricular ectopic beats was found to give too many falsepositives, and therefore all hours with more than five ectopic beats had to be printed on paper (running at $4.2 \mathrm{~mm} / \mathrm{s}$ ) while hours with less than five ectopic beats were evaluated visually from the oscilloscopes.

As a preliminary analysis a slow speed paper print for heart rate counts was recorded and at the same time a skilled technician checked on the oscilloscope whether any arrhythmias occurred. All tapes that seemed to be without arrhythmias were rechecked visually by another technician. The tapes with arrhythmias were later checked by the participating physiologist (BS). In cases of complicated arrhythmias or doubtful nature of the ectopic beats, printouts at $50 \mathrm{~mm} / \mathrm{s}$ were used. All analyses were made without knowledge of the activity or occupation of the recorded subject.

\section{PROTOCOLS}

The average heart rate for each 30 -minute period was evaluated from the slow speed frequency paper prints. The number and quality of ectopic beats or arrhythmias were notified on individual protocols for each recorded hour without knowledge of the activity and exposure status of the subject. After the analyses of the recordings were finished, the mean heart rate, the number of ectopic beats, etc were summarised for different periods of exposed hours, working hours without exposure, leisure hours awake, and sleeping hours for the respective 24-hour period.

QT -TIMES

The QT-intervals were measured from five nonconsecutive beats and corrected for the heart rate according to Bazett's ${ }^{16}$ formula: $\mathrm{QT}_{\mathrm{c}}=\frac{\mathrm{QT}}{\sqrt{\mathrm{RR}}}$.

Those calculations were made from three different periods in each 24-hour recording.

\section{DATA ANALYSIS}

All the information on the subjects and the ECG recordings was computerised, and a data set comprising the 85 subjects and 64 basic variables was formed. From this original data set new combinations of variables for the analyses of specific hypothesis could be created.
The main part of the statistical analysis has been devoted to the analysis of dichotomised variables describing presence or non-presence of factors such as exposure to dynamite, appearance of ectopic beats, smoking, age over 40 years, and known heredity for cardiovascular diseases. Distributionfree as well as distribution-dependent tests were used in the analysis of the original metric variables. Twotailed p-values were calculated where so applicable. Classified as non-significant results are those for which $\mathrm{p}>0.05$.

\section{Exposure}

Dynamite consists of about $60 \%$ inorganic nitrates, $25 \%$ blasting oil, $10 \%$ dinitrotoluene, and a few per cent nitrocellulose and fillers-for instance, wood flour and chalk. The blasting oil consisted of $80 \%$ nitroglycol and $20 \%$ nitroglycerin at the studied industry in 1977-8. Exposure monitoring for nitrate esters was performed by ten-minute sampling in the breathing zone of exposed workers in every production house each autumn and spring. The manufacturing processes and details about the exposure monitoring device as well as the analytic procedures at the studied industry have been described elsewhere. ${ }^{\text {? }}$

The number of recorded subjects in different operations and the calculated mean 8-hour timeweighted average (TWA) concentrations of nitroglycol, which completely dominates the vapours from the blasting oil, are displayed in table 1 .

Table 1 Number of dynamite workers in different operations and the calculated mean 8-hour TWAconcentration of nitrate esters from short-time samples in 1977-8

\begin{tabular}{lcll}
\hline $\begin{array}{l}\text { Type of operation } \\
\text { Nubjects }\end{array}$ & $\begin{array}{l}\text { No of recorded } \\
\text { samples }\end{array}$ & $\begin{array}{l}\text { No sht-time } \\
\text { satroglycol } \\
\text { concentration } \\
\left(\mathrm{mg} / \mathrm{m}^{3}\right)\end{array}$ \\
\hline Nitration & 3 & - & $<0 \cdot 1$ \\
Washing & 1 & - & $<0 \cdot 1$ \\
Mixing & 12 & 14 & $0 \cdot 5$ \\
Cartridge filling & 19 & 51 & $0 \cdot 9$ \\
Packing & 5 & 10 & $0 \cdot 1$ \\
Transporting & 1 & 2 & $<0 \cdot 1$ \\
Repairing & 1 & - & Unknown \\
\hline
\end{tabular}

Thirty-one subjects were employed in the more heavily exposed operations of mixing and cartridge filling while 10 were exposed to low concentrations of nitrate esters (unknown for one). The eight-hour TWA-concentrations have been calculated by taking the mean value of each operation from the exposure measurements during the autumn of 1977 and the spring of 1978 and adjusting for the mean number of hours in exposed work - that is, the exposure measurements were not taken during the actual work 
shifts when ECG were recorded. Nitration, washing, and most of the mixing are automated operations, and the operators are only exposed for shorter times and then instructed to wear breathing protective equipment as well as gloves, which, however, does not exclude exposure as nitroglycol vapours are absorbed in the gloves and secondarily through the skin. ${ }^{17}$

\section{Results}

The main purpose of the study was to compare the frequency of cardiac disturbances during an exposed work shift and a period 40-64 hours after the last contact with nitrate esters among dynamite workers and controls at the corresponding time. Therefore, five dynamite workers had to be excluded from the analyses as they were not exposed during the Friday shift, due to temporary replacements. Technical tape recorder failures made analyses impossible from the recordings of seven subjects-five controls and two dynamite workers. Thus the reported calculations have been performed on recordings from 42 dynamite workers and 43 controls.

The dynamite workers and the controls were comparable in age distribution, smoking habits, height, weight, blood pressure, and cholesterol concentration (table 2). The dynamite workers stated a somewhat higher average alcohol consumption than the controls $(\mathrm{p}=\mathbf{0} \cdot 11)$ but no more than the Swedish average consumption, $4.5 \mathrm{~kg} / \mathrm{yr}$ among men. ${ }^{15}$ Twenty and a half per cent of the dynamite workers and $42.9 \%$ of the controls had close relatives who had died from or had been treated for heart disease or hypertension before the age of $61(p=0.06)$.
The total number of observed ventricular ectopic beats (VEB) and supraventricular ectopic beats (SVEB) were 6623 and 7766 respectively. These numbers were heavily influenced by a few subjects with large numbers of extrasystoles (table 3). The mean values of the individual mean number of VEB per hour or per 10000 heart beats were rather similar in the two groups. For the SVEB variables there was a tendency towards larger mean values for the exposed group, but they were not significantly different from those of the control group.

The difference in the mean number of ectopic beats per hour and per 10000 heart beats respectively between the second and the first 24-hour period was studied according to the hypothesis that exposed dynamite workers might have an increased number of cardiac disturbances in the abstinence phase but no statistically significant differences were found (table 4). In fact the tendency seemed to be the reverse, but the figures are heavily influenced by a few subjects with large numbers of ectopic beats.

Table 5 shows the frequency distribution for the individual mean number of ectopic beats an hour during the two periods of observation, separately and together. The class limits have been chosen to be analogous with those used in some previous studies. ${ }^{1819}$ The distribution is skew with very few individuals in the classes with more than five VEB an hour on average. There are no significant differences between the two groups, either separately or together.

Further analyses were made concerning the number of workers in the respective group displaying any VEB or SVEB. Thirty-five subjects showed at least one VEB during the 48-hour recording, 43 at least one SVEB, and 34 had no extrasystoles at all.

Table 2 Background information for 42 exposed dynamite workers and 43 unexposed controls

\begin{tabular}{|c|c|c|c|c|c|c|c|c|c|c|c|c|c|c|c|c|c|}
\hline & \multicolumn{3}{|l|}{ Age } & \multirow{3}{*}{$\begin{array}{l}\text { Heredity } \\
\text { for } \\
C V D^{*}\end{array}$} & \multirow{3}{*}{$\begin{array}{c}\text { Height } \\
\text { (cm) }\end{array}$} & \multirow{3}{*}{$\begin{array}{l}\text { Weight } \\
(k g)\end{array}$} & \multicolumn{4}{|c|}{ Blood pressure } & \multirow{2}{*}{\multicolumn{2}{|c|}{$\begin{array}{l}\text { Cholesterol } \\
(\mathrm{mmol} / \mathrm{l})\end{array}$}} & \multirow{2}{*}{\multicolumn{2}{|c|}{$\begin{array}{l}\text { Alcohol } \\
\text { (kg/year) }\end{array}$}} & \multicolumn{3}{|c|}{ Smoking habits } \\
\hline & \multirow[t]{2}{*}{ Mean } & \multirow[t]{2}{*}{$S D$} & \multirow[t]{2}{*}{ Range } & & & & \multicolumn{2}{|c|}{ Systolic } & \multicolumn{2}{|c|}{ Diastolic } & & & & & \multirow{2}{*}{ Smokers } & \multirow{2}{*}{$\begin{array}{l}\text { Ex- } \\
\text { smokers }\end{array}$} & \multirow{2}{*}{$\begin{array}{l}\text { Never } \\
\text { smoked }\end{array}$} \\
\hline & & & & & & & Mean & $S D$ & Mean & $S D$ & Mean & $S D$ & Mean & $S D$ & & & \\
\hline $\begin{array}{l}\text { Exposed } \\
\text { Controls }\end{array}$ & $\begin{array}{l}36 \cdot 4 \\
38 \cdot 1\end{array}$ & $\begin{array}{l}13 \cdot 8 \\
10 \cdot 9\end{array}$ & $\begin{array}{l}18-62 \\
21-61\end{array}$ & $\begin{array}{r}8 \\
18\end{array}$ & $\begin{array}{l}177 \\
176\end{array}$ & $\begin{array}{l}77 \\
75\end{array}$ & $\begin{array}{l}128 \\
128\end{array}$ & $\begin{array}{r}12 \cdot 7 \\
9 \cdot 0\end{array}$ & $\begin{array}{l}76 \\
74\end{array}$ & $\begin{array}{r}10 \cdot 6 \\
8 \cdot 8\end{array}$ & $\begin{array}{l}5 \cdot 8 \\
5 \cdot 7\end{array}$ & $\begin{array}{l}1.0 \\
0.8\end{array}$ & $\begin{array}{l}3.0 \\
1.7\end{array}$ & $\begin{array}{l}4 \cdot 4 \\
2 \cdot 3\end{array}$ & $\begin{array}{l}24 \\
21\end{array}$ & $\begin{array}{l}6 \\
9\end{array}$ & $\begin{array}{l}12 \\
13\end{array}$ \\
\hline
\end{tabular}

*See text for definition.

Table 3 Number of analysed hours, total amount, and range of observed ectopic beats for individuals, and individual mean number of ectopic beats per hour respectively per 10000 heart beats $\left(10^{4} \mathrm{hb}\right)$

\begin{tabular}{|c|c|c|c|c|c|c|c|c|c|}
\hline & \multirow{2}{*}{$\begin{array}{l}\text { Analysed } \\
\text { hours }\end{array}$} & \multicolumn{2}{|l|}{$V E B$} & \multicolumn{2}{|c|}{$S V E B$} & \multicolumn{2}{|l|}{$V E B$} & \multicolumn{2}{|c|}{$S V E B$} \\
\hline & & Total & $\begin{array}{l}\text { Range for } \\
\text { individuals }\end{array}$ & Total & $\begin{array}{l}\text { Range for } \\
\text { individuals }\end{array}$ & $\begin{array}{l}\text { Per } \\
\text { hour }\end{array}$ & $\begin{array}{l}\text { Per } \\
10^{4} h b\end{array}$ & $\begin{array}{l}\text { Per } \\
\text { hour }\end{array}$ & $\begin{array}{l}\text { Per } \\
10^{4} h b\end{array}$ \\
\hline $\begin{array}{l}\text { Exposed } \\
\text { Controls }\end{array}$ & $\begin{array}{l}1768 \\
1823\end{array}$ & $\begin{array}{l}2769 \\
3854\end{array}$ & $\begin{array}{l}0-1294 \\
0-3245\end{array}$ & $\begin{array}{r}7181 \\
585\end{array}$ & $\begin{array}{l}0-2988 \\
0-269\end{array}$ & $\begin{array}{l}1 \cdot 5 \\
2 \cdot 2\end{array}$ & $\begin{array}{l}3 \cdot 3 \\
5 \cdot 5\end{array}$ & $\begin{array}{l}4 \cdot 1 \\
0 \cdot 3\end{array}$ & $\begin{array}{r}10 \cdot 6 \\
0.8\end{array}$ \\
\hline
\end{tabular}


Table 4 Difference between 2nd and 1st 24-hour period concerning mean number of ectopic beats per hour and per 10000 heart beats

\begin{tabular}{|c|c|c|c|c|}
\hline & \multicolumn{2}{|l|}{$V E B$} & \multicolumn{2}{|l|}{$S V E B$} \\
\hline & Per hour & $\operatorname{Per} 10^{4} \mathrm{hb}$ & Per hour & $\operatorname{Per} 10^{4} \mathrm{hb}$ \\
\hline $\begin{array}{l}\text { Exposed } \\
\text { Controls }\end{array}$ & $\begin{array}{r}-1.35 \\
1.36\end{array}$ & $\begin{array}{c}-3 \cdot 0 \\
3 \cdot 17\end{array}$ & $\begin{array}{r}-0.76 \\
0 \cdot 10\end{array}$ & $\begin{array}{r}-2.64 \\
0.12\end{array}$ \\
\hline
\end{tabular}

The proportion of subjects with and without VEBs and SVEBs respectively was similar in the two groups. For those subjects, however, who showed ectopic beats in only one of the two 24-hour periods there was a tendency in the dynamite group for these to be in the second period (table 6). For the controls the opposite was true for VEB, whereas a more uniform distribution was obtained for SVEB. The difference between the two groups was statistically significant for VEBs ( $p=0.05$; Fisher's exact test) but not so for SVEBs.

The subjects were further dichotomised for age (younger or older than $\mathbf{4 0}$ years), exposure, smoking status (smoker/non-smoker), and appearance or nonappearance of VEB/SVEB during the 48-hour recording. Age was the only factor that contributed significantly to the appearance of ectopic beats (chisquare tests). Multiple regression analysis was used to obtain the direction of the influence of the independent variables (table 7). Smoking habits and exposure contributed differently but non-significantly with respect to VEB and SVEB. Furthermore, no statistically significant differences were obtained with either three-way analysis of variance of VEB and SVEB per hour or per $10^{4}$ heart beats (in logarithmic scale) or in analysis of covariance (with the exact data of age as covariate).

"Complicated" VEBs (multifocal, bigemeny, or coupled) were seen in six dynamite workers and four controls (table 8 ). The only observed period of ventricular tachycardia (seven beats) was seen in a dynamite worker just after getting out of bed on Monday morning at 0330.

Table 8 Number of workers with "complicated" VEBs

\begin{tabular}{llllll}
\hline & Bigemeny & Multifocal Coupled & $V T$ & $\begin{array}{l}\text { Total No } \\
\text { with } \\
\text { complicated } \\
\text { VEB }\end{array}$ \\
\hline Exposed & 3 & 3 & 2 & 1 & 6 \\
Controls & 2 & 3 & 1 & 0 & 4 \\
\hline
\end{tabular}

Table 5 Frequency distribution for number of ectopic beats an hour during two 24-hour periods

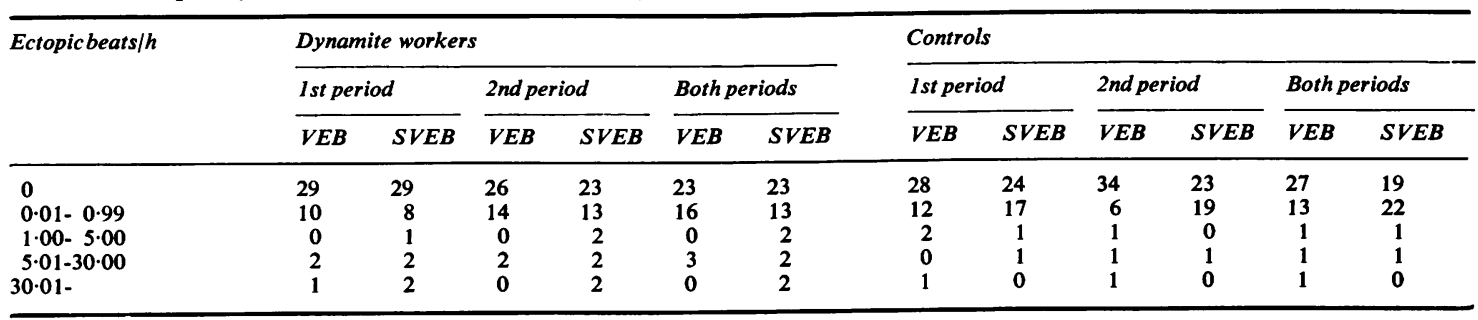

Table 6 Number of workers dichotomised on having ectopic beats or not in two 24-hour periods

\begin{tabular}{|c|c|c|c|c|c|c|c|c|}
\hline & \multicolumn{2}{|c|}{ Both periods } & \multicolumn{2}{|c|}{$V E B$ exclusively in period } & \multicolumn{2}{|c|}{ SVEB exclusively in period } & \multicolumn{2}{|c|}{ Neither period } \\
\hline & $V E B$ & $S V E B$ & $1 s t$ & $2 n d$ & $1 s t$ & $2 n d$ & $V E B$ & $S V E B$ \\
\hline $\begin{array}{l}\text { Exposed } \\
\text { Controls }\end{array}$ & $\begin{array}{r}10 \\
8\end{array}$ & $\begin{array}{l}13 \\
15\end{array}$ & $\begin{array}{l}3 \\
7\end{array}$ & $\begin{array}{l}6 \\
1\end{array}$ & $\begin{array}{l}0 \\
4\end{array}$ & $\begin{array}{l}6 \\
5\end{array}$ & $\begin{array}{l}23 \\
27\end{array}$ & $\begin{array}{l}23 \\
19\end{array}$ \\
\hline
\end{tabular}

Table 7 Regression coefficients in multiple regression analyses of appearance of ventricular and supraventricular ectopic beats on dichotomised variables for exposure to dynamite, age over 40, smoker, and interaction factors

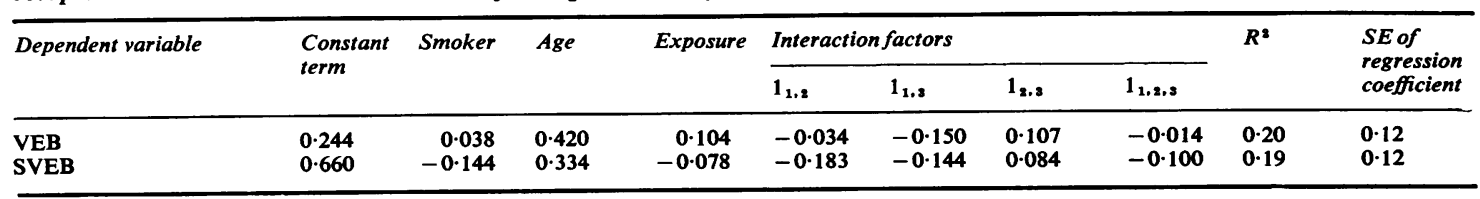


The mean of the corrected QT-times was similar for the two groups in each of the six calculated periods, and there was no tendency towards longer QT-times during the abstinence phase for the dynamite workers.

\section{Discussion}

The validity of a study of this kind and the conclusions that may be drawn depend on the comparability in background variables for the exposed group and the controls, the probability of detecting serious cardiac disturbances during the recorded time, and the relevance of continuous ECG monitoring for the observation of such cardiac disturbances as well as the analytical and statistical treatment.

\section{COMPARABILITY OF STUDY GROUPS}

The dynamite workers were comparable with the control group in most background variables, but hereditary background and stated alcohol consumption differed. Neither heredity nor alcohol consumption, however, correlated with the occurrence of ectopic beats according to multiple regression analyses.

Chronic alcoholism has been associated with heart disease and cardiac arrhythmias, particularly atrial fibrillation, ${ }^{20}$ but the effect of moderate alcohol consumption in normal men seems to be more uncertain. ${ }^{15}$

Since the late 1950s health check-ups with increasing strictness for cardiac risk factors have been performed in the studied industry, and no one with signs of suspected heart disease has been allowed to continue in exposed work. Of the dynamite workers, 31 had had health check-ups at least once as well as the examination preceding this study. Some of these had been examined more than 20 times, while the controls were screened only once for selection to this study. Increasing time of ECG recording has been shown to increase the detection of cardiac disturbances. ${ }^{21}$ Therefore, the dynamite workers have been better screened for cardiac disturbances and might have had a more favourable "heart health state."

CONTINUOUS ECG MONITORING FOR

DETECTING SERIOUS CARDIAC

DISTURBANCES

Twenty-four-hour ECG monitoring was found to detect more ventricular ectopic activity and repetitive forms, such as couplets and ventricular tachycardia, compared with exercise tests in cardiac patients. ${ }^{22}$ No study of comparison between exercise test and 24-hour ambulatory monitoring among healthy subjects has been found, but continuous recording during normal activity has some attraction as it more accurately reflects the real condition and covers much longer times and more activities. Nevertheless, 24-hour recording for routine health check-ups imposes considerable strains on the medical health service, the analysing physiological laboratory, and the monitored subjects.

Risk factors for mortality among people with evidence of coronary heart disease might differ from those operating in subjects without such signs-for instance, Rose $e^{t}$ al $^{23}$ found no correlation between VEBs on short-time ECG or $\mathrm{QT}_{\mathrm{c}}$ among healthy men initially free of evidence of ischaemia and subsequent deaths from coronary heart disease. Furthermore, smokers and non-smokers had similar frequency and quality of cardiac disturbance in this study, as well as in another, ${ }^{18}$ although smoking is a well-known risk factor for increased cardiac mortality. ${ }^{24}$ An excess frequency of myocardial infarction was reported among staff workers compared with production line-workers in a car assembly factory, but no differences were found with 24-hour ambulatory ECG monitoring. ${ }^{25} 26$

Sudden deaths among dynamite workers are not very frequent per se, although they have been reported in excess frequency compared with the average population. ${ }^{2}$ In the studied plant, where about 100 people have been employed in the dynamite line at the same time, only one accepted case of "Monday death" has occurred during the past 25 years (and three more cases have been discussed). Ventricular fibrillation is a rare phenomenon among cardiac patients and cannot be expected to occur among healthy subjects. ${ }^{27}$ The frequencies of ectopic beats noticed both among the dynamite workers and the controls agree reasonably well with the frequencies among healthy men reported by others. ${ }^{18} 26$

Ventricular tachycardia has been observed only occasionally among those screened for cardiac risk factors. ${ }^{921}$ Therefore, the single period of ventricular tachycardia observed in this study in a dynamite worker during the abstinence phase and just after getting out of bed on Monday morning, might be of some interest. This 51-year-old man had worked with dynamite for 22 years, firstly as a heavily exposed mix-house worker but during later years as TV-supervisor with exposure only during 30-60 minutes a shift. He was a moderate smoker and drinker and health check-up examinations over 20 years had shown perfectly normal resting ECGs, but his record included 981 VEBs altogether during the 48-hour period. This episode of ventricular tachycardia might have resulted from cardiac affection from mechanisms affected during the abstinence phase in a sensitive person. 
ANALYTICAL AND STATISTICAL

\section{CONSIDERATIONS}

The possibility of erroneous interpretations of the tapes has been limited by the procedure with printouts for all hours with more than five ectopic beats and not trusting the automatic counter system usually used in this type of studies. Such systems might be quite sufficient for clinical and gross comparison but not for the exact calculations considered necessary in this study. Furthermore, all questionable beats or periods have been printed out with the normal rate and evaluated by an experienced physiologist.

There are some difficulties in quantifying and analysing the results from continuous ECG recordings among healthy subjects. The distribution of observed arrhythmias was skew as many subjects did not show any abnormalities, while a few subjects had large numbers of ectopic beats. Most of these analyses have been based on binary variables and distribution-free methods for statistical testing, not relying on specific normality or homoscedasticity assumptions.

The applied methods are considered valid since they are robust, adapted to the actual distributional properties of the data under study, and due to the close similarity between the conclusions reached with all the tests.

Some of the background variables have been introduced in the analyses, but a more detailed study of their influence was limited by the relatively small number of subjects available for recording.

\section{SUMMARY AND CONCLUSION}

No significant differences were observed between the dynamite workers and the control group in respect of the mean number of ectopic beats per hour or per 10000 heart beats, and the frequency of subjects with any ectopic beat was also similar in the two groups. Among those who showed only ectopic beats during one of the two periods, more dynamite workers than controls showed ectopic beats during the second period, but the tendency was not very strong and the numbers were small. Furthermore, the mean QTtime was not longer during the abstinence phase compared with periods around or directly after exposure.

The results should not be taken as a guarantee that the present exposure levels are safe for either acute or chronic cardiac effects. Risk factors for manifest heart disease and sudden deaths among people with signs of coronary heart disease might not have the same prognostic value in healthy subjects without such signs. On the other hand, the results do not urge for diminished exposure levels.

Several cases with complicated and large numbers of VEBs were detected by continuous recording but not so on repeated short-time ECGs. The accomplishment of this study shows that continuous ECG monitoring could be used for ambulatory surveillance of cardiac disturbances in active workers.

We thank Lena Janzon and Margareta Gunnarsson at the Nitro Nobel Company for performing the recordings, Birgitta Fält and Siw Persson at the Department of Clinical Physiology for technical assistance, and Professor Olav Axelson, University of Linköping, for comments on the manuscript. The study was sponsored by the Swedish Work Environment Fund, contract number 77/131.

\section{References}

1 Symanski H. Schwere Gesundheitsschädigungen durch berufliche Nitroglykoleinwirkung. Arch Hyg Bakteriol 1952;136:139-58.

${ }^{2}$ Carmichael P, Lieben J. Sudden death in explosives workers. Arch Environ Health 1963;7:424-9.

${ }^{3}$ Lange RL, Reid MS, Tresch DD, Keflan MH, Bernhard VM. Nonatheromatous ischemic heart disease following withdrawal from chronic industrial nitroglycerin exposure. Circulation 1972;46:666-78.

${ }^{4}$ Hogstedt C, Axelson O. Nitroglyerine-nitroglycol exposure and the mortality in cardio-cerebrovascular diseases among dynamite workers. J Occup Med 1977;19:675-8.

${ }^{5}$ Hogstedt C, Andersson K. A cohort study on mortality among dynamite workers. J Occup Med 1979;21:553-6.

- National Institute for Occupational Safety and Health. Criteria for a recommended standard. Occupational exposure to nitroglycerine/nitroglycol. Rockville: US DHEW, 1978.

' Hogstedt C, Davidsson B. Nitroglycol and nitroglycerine in a dynamite industry 1958-78. Am Ind Hyg Assoc J $1980 ; 41: 373-5$.

- Yoshikawa H. Effect of adrenaline on nitroglycol poisoned mice. Ind Health 1964;2:127-8.

- Clark DG. The supersensitivity of the rat cardiovascular system to epinephrine after repeated injections of ethylene glycol dinitrate. Toxicol Appl Pharmacol 1970;17: 433-42.

${ }^{10}$ Schwartz PJ, Wolf S. QT interval prolongation as predictor of sudden death in patients with myocardial infarction. Circulation 1978;57:1074-7.

${ }^{11}$ Chiang BN, Perlman LV, Ostrander LD Jr, Epstein FH. Relationship of premature systoles to coronary heart disease and sudden death in the Tecumseh epidemiologic study. Ann Intern Med 1969;70:1159-66.

12 Hinkle LE, Carver ST, Argyros DC. The prognostic significance of ventricular premature contractions in healthy people and in people with coronary heart disease. Acta Cardiol 1974; suppl XVIII, 5-32.

${ }^{13}$ Rose G, Blackburn H. Cardiovascular survey methods. Geneva: World Health Organisation Monograph Series No 56, 1968.

14 Doll R, Hill AB. Lung cancer and other causes of death in relation to smoking. $\mathrm{Br}$ Med J 1956;ii:1071-81.

${ }_{15}$ Myrhed M. Alcohol consumption in relation to factors associated with ischemic heart disease. A co-twin control study. Acta Med Scand 1974; suppl 567.

${ }^{16}$ Bazett HC. An analysis of the time relations of electrocardiograms. Heart 1920;7:353-70. 
${ }^{17}$ Hogstedt C, Ståhl R. Skin absorption and protective gloves in dynamite work. Am Ind Hyg Assoc J 1980;41: 367-72.

${ }^{18}$ Clarke JM, Hamer J, Shelton JR, Taylor S, Venning GR. The rhythm of the normal human heart. Lancet 1976; ;i: 508-12.

19 Lown B, Calvert AF, Armington R, Ryan M. Monitoring for serious arrhythmias and high risk of sudden death. Circulation 1975;51-2, suppl III :189-98.

${ }^{20}$ Brigden W, Robinson J. Alcoholic heart disease. Br Med J 1964 ;ii:1283-9.

${ }^{21}$ Kennedy HL, Chandra V, Sayther KL, Caralis DG. Effectiveness of increasing hours of continuous ambulatory electrocardiography in detecting maximal ventricular ectopy. Am J Cardiol 1978;42:925-30.

${ }^{22}$ Ryan M, Lown B, Horn H. Comparison of ventricular ectopic activity during 24-hour monitoring and exercise testing in patients with coronary heart disease. $N$ Engl $J$ Med 1975;292:224-9.

${ }^{23}$ Rose G, Baxter PJ, Reid DD, McCartney P. Prevalence and prognosis of electrocardiographic findings in middle-aged men. Br Heart J 1978;40:636-43.

${ }^{24}$ Astrup P, Kjeldsen K. Carbon monoxide, smoking, and atherosclerosis. Med Clin North Am 1973;58:323-50.

${ }^{25}$ Baxter PJ, White WG, Sanderson CFB, Barnes GM, Baxter CS, Acheson RM. Myocardial infarction in car assembly workers. $\mathrm{Br} J$ Ind Med 1976;33:1-8.

${ }^{26}$ Baxter PJ, White WG, Barnes GM, Cashman PMM. Ambulatory electrocardiography in car workers. Br J Ind Med 1978;35:99-103.

${ }^{27}$ Hiss RG, Averill KH, Lamb LE. Electrocardiographic findings in 67375 asymptomatic subjects. III Ventricular rhythms. Am J Cardiol 1960;6:96-107. 